\title{
Impacto del paradigma neoliberal en el curriculum venezolano, durante los gobiernos de COPEI y acción democratica (1970-1998)
}

\author{
Impact of the neoliberal paradigm in \\ the venezuelan curriculum, during COPEI governments and \\ democratic action (1969-1998)
}

\author{
José Pascual Mora-García \\ Orcid: http://orcid.org/0000-0002-5345-6808 \\ Profesor Titular Emérito de la Universidad de Los Andes, Tachira, Venezuela, \\ pascualmoraster@gmail.com
}

Received on 15/01/2020 - Approved on 10/02/2020

\begin{abstract}
Resumen
Los gobiernos democráticos de los partidos políticos Copei y Acción democrática se alternaron el poder en Venezuela entre 1969-1998, y fue precisamente en esta etapa que emerge el paradigma neoliberal educación. En primer lugar, nos proponemos develar que las teorías del Curriculum recibieron su impacto y tipificaron un modelo educativo que fue privilegiando al llamado "darwinismo social" en el que se privilegia a los sectores de mejores ingresos económicos y marginando los sectores más vulnerables. El presente estudio se conecta con una línea de investigación que analiza las historia del currículum en Venezuela, cuyos resultados han sido presentados a la comunidad científica en informes precedentes, (Mora-García, 2004; Mora-García, 2013; Mora-García, 2014; Rojas \& Mora-García, 2019). Se realiza una revisión nueva de la literatura especializada en la relación neoliberalismo y curriculum, con la finalidad de establecer propuestas y conclusiones válidas. Son aproximaciones que nos dan nuevas luces sobre un tema que requiere ser analizado recurrentemente.
\end{abstract}

Palabras clave: Neoliberalismo. Curriculum. Capital intelectual.

\section{Abstract}

The democratic governments of the political parties Copei and Democratic Action alternated power in Venezuela between 1969 - 1998, and it was precisely at this stage that the neoliberal education paradigm emerges. In the first place, we propose to reveal that the theories of the Curriculum received their impact and typified an educational model that was privileging the so-called "social Darwinism" in which the sectors with the best economic income and marginalizing the most vulnerable sectors are privileged. The present study connects with a line of research that analyzes the history of the curriculum in Venezuela, whose results have been presented to the scientific community in previous reports, (Mora-García 2004; Mora-García, 2013; Mora-García, 2014; Rojas \& Mora-García, 2019). A new review of the specialized literature on the neoliberalism and curriculum relationship 
is carried out, in order to establish valid proposals and conclusions. These are approaches that give us new lights on a subject that needs to be analyzed repeatedly.

Keywords: Neoliberalism. Curriculum. Intellectual capital.

\section{Introducción}

El modelo neoliberal ha sido definido de manera polisémica, pero hay al menos tres puntos en común: 1. Sostener la tesis de acercamiento con el primer mundo, 2. Magnificar las directrices de la empresa privada frente al Estado, el Estado pasaba a jugar un rol subalterno; "el papel del Estado es atrofiado, reducido y regulado por la lógica del mercado." (Herrera, 2015, p. 1) En ese sentido, el desiderátum era potenciar al Mercado y debilitar al Estado; en consecuencia, el mandato era privatizar las empresas estatales y reducir el tamaño del Estado. Y, 3. Potenciar la formación de las elites intelectuales como clase hegemónica, lo cual trajo consecuencias en los sectores más vulnerables. Esta tesis se puede desprender del libro La Generación de Relevo Vs. el Estado Omnipotente, que sirvió de Manual para el Proyecto Neoliberal venezolano, de un representante del llamado Grupo Roraima, Marcel Granier (1985).

Debemos aclarar de entrada que el desarrollo del modelo emergente neoliberal no fue el simple seguimiento de una cartilla, sino que se fue amoldando a diversos escenarios para introducirse en los países latinoamericanos, y uno de esos escenarios fue a través de las teorías del curriculum. Los Estados tenían que lidiar paradójicamente entre la tesis del Estado bienestar, que se habían adoptado en gran parte de América Latina, en donde el rol del Estado era definido como: Mega-actor, intervencionista, asistencialista y empresario. $Y$ al mismo tiempo, dar cabida al modelo subterráneo que se desarrollaba como un "caballo de Troya" en el curriculum oculto y oficial, para impulsar la ideología liberal basada en la tesis de Adam Smith de una "mano invisible" que regula las acciones de los hombres y ejercía una influencia saludable sobre el mercado.

Como historiadores abordamos siempre los procesos históricos en el tiempo de larga duración, lo que Braudel denomina tiempo estructural, por eso partimos de la hipótesis de que el modelo neoliberal tiene raíces desde los años 50, con la presencia del denominado Paradigma Economicista en Educación (Tedesco, 1986);

Existe un consenso relativamente amplio en considerar que el desarrollo de la
investigación socio-educativa estuvo enmarcado históricamente en tres
grandes paradigmas dominantes en diferentes momentos históricos: el
paradigma de la teoría educativa liberal; el paradigma economicista (capital
humano, recursos humanos, etc.) y el paradigma de los enfoques crítico-
reproductivistas (...) Dentro del conjunto de enfoques de corte economicista,
la teoría del "capital humano" brindó una base consistente a un nuevo
programa de investigaciones, que tuvo una influencia y desarrollo muy
significativos. Las preguntas centrales del paradigma del capital humano
giraron alrededor de las diferencias de ingresos entre los individuos. De
acuerdo a la explicación del capital humano, dichas diferencias serían la
expresión de distintos niveles de capacidad productiva y la capacidad
productiva estaría en función de los años de escolaridad. Sobre esta base, se
llevaron a cabo numerosos estudios sobre educación, distribución de ingresos,
mercado de empleo, financiamiento, etc., que colocaron a la economía de la 
educación como disciplina hegemónica dentro del conjunto de las llamadas "ciencias de la educación. (Tedesco, 1986, p. 1ss).

Pero ese proceso se consolida en la Educación venezolana con la presencia de las teorías curriculum en la década del 70 , especialmente con el Eficientismo social de Raph Tyler. A pesar de que las tesis de Tyler se remontan a la década del 30 del siglo pasado, su influencia en América Latina es tardía como lo demuestran los estudios realizados por Díaz, Barriga \& García Garduño, 2014. En los primeros años de la década de los treinta, Ralph Tyler acuñó el término evaluación educacional y publicó su comprensión del currículo y la evaluación. En unos quince años desarrolló sus investigaciones hasta macerar el método, cuya principal característica se centraba en unos objetivos claramente fijados. De hecho, definía la evaluación en función de alcanzar los objetivos. Por eso la evaluación estaba en función del rendimiento de los estudiantes, que había sido precisamente determinado a través de la realización de un currículo. Los objetivos resultantes, referidos al rendimiento, proporcionaban entonces la base para elaborar un currículo y un test de desarrollo. La elaboración del currículo estaba sujeta a dos variables, por un lado, los contenidos que debían aprenderse, y por otro, por la evolución del rendimiento de los estudiantes. La visión de Tyler se generalizó con la llamada tecnología de los tests de desarrollo, los tests relacionados con los objetivos, y también a los relacionados con las diferencias individuales y con las normas nacionales o del estado. Ya a mediados de los años 40 del siglo pasado, Ralph Tyler había conseguido la aceptación de la comunidad científica como para ejercer una gran influencia en los siguientes 30 años; y efectivamente, así sucedió sobre América Latina.

Como consecuencia del lanzamiento del Sputnik I en 1957, el gobierno federal respondió promulgando la National Defense Education Act de 1958, el método Tyler fue usado para definir los objetivos de los nuevos currículos y para valorar el grado en que estos objetivos quedaban, entre otras cosas. Las tesis de Tyler recibirán fuertes críticas en la década del 60 en la sociedad americana. Esta valoración negativa fue reflejada en un histórico artículo de Cronbach (1963) en donde criticó duramente los conceptos en los que se habían basado las evaluaciones por su falta de relevancia y utilidad, y aconsejó a los evaluadores que se dedicaran a hacer evaluaciones basadas en comparaciones de los resultados obtenidos en tests tipificados, por grupos experimentales y de control.

La década del 70 del siglo pasado marcará cambios que servirán para profundizar los criterios de la evaluación educacional, así Phi Delta Kappa creó el National Study Committee on Evaluation (Stufflebeam y otros, 1971). Este comité concluyó que la evaluación educacional recomendó el desarrollo de nuevas teorías y métodos de evaluación. Al mismo tiempo, empezaron a aparecer nuevas conceptualizaciones sobre la evaluación PROVUS (1971), Hammond (1967), Eisner (1967) y Metfessel y Michael (1967) propusieron una reforma del modelo Tyler. Glaser (1963), Tyler (1967) y Popham (1971) apostaron por los tests basados en normas. Cook (1966) pidió la utilización del método de análisis sistemático para la evaluación de programas. Scriven (1967), Stufflebeam (1967, 1971) y Stake (1967) crearon nuevos modelos de evaluación que se alejaban radicalmente de los métodos anteriores. De un modo creciente, la especialidad está considerando la metaevaluación (Scriven, 1975; Stufflebeam, 1978) como un medio para asegurar y comprobar la calidad de las evaluaciones. 
Una mirada al campo intelectual del desarrollo crítico de las teorías del curriculum en la región latinoamericana nos permite constatar que ha sido precaria, a manera de ejemplo citamos las más reconocidas: Brasil (Moreira, 1990; 2003; Lopes y Macedo, 2003), México (Díaz Barriga, 1985; 2003, 2014), Argentina (Palamidessi y Feldman, 2003), Chile (Magendzo, 1986; 1999; 2008; 2014); Venezuela (Mora-García, 2000, 2004, 2009, 2014) si los comparamos con los realizados en EEUU (Kliebard, 1986; Tanner y Tanner, 1975; Cremin, 1964, García Garduño, 1995). Recientemente se realizó un estudio de las comunidades científicas de la Evolución del Curriculum en América Latina y nos permite constatar la afirmación, estudio dirigido por Ángel Díaz Barriga y José María García Garduño (2014).

En nuestro estudio nos acercamos al tema central sobre la instalación del paradigma Neoliberal en Venezuela, para lo cual tendríamos que decir que fue un proceso que se inicia desde la década del 50, con la emergencia del paradigma desarrollista en América Latina. Es una línea de investigación cuyos resultados han sido presentados en los siguientes trabajos: Mora García, José Pascual (2000) Universidad, Curriculum y Postmodernidad Crítica. UPEL-UNEXPO: Barquisimeto-Venezuela; (2004) "El curriculum como historia social" Teoría y Didáctica de las Ciencias Sociales. Enero-diciembre, № 9, 2004. Pp. 49-74; (2013) "Historia del curriculum en Venezuela: fuentes y comunidades académicas (19361999)" Revista de Historia de la Educación Colombiana (Rhec). Vol. 16. No. 16, enero-diciembre, pp. 213-243; (2013) "Las reformas en la historia del currículo en Venezuela (el proceso de implantación de la educación básica 1980-1998)" en Revista de Historia de la Educación Latinoamericana (RHELA), vol.15 no.21; (2018) "Políticas educativas de enseñanza del Curriculum en Venezuela: 19111998" Educere. Año 22 - № 72 - Mayo - Agosto 2018 / 353 - 374. Y nuestro capítulo de libro, en la obra colectiva: José Pascual Mora-García, (2014) "El curriculum en Venezuela: del eficientismo social de Rath Tyler a la postmodernidad (1970-1997)" en DÍAZ BARRIGA, Ángel et José María Garduño (Coordinadores) Desarrollo del Curriculum en América Latina. Miño \& Dávila. Bs. As. Argentina.

El estudio del currículum en Venezuela no es abordado como un bloque disciplinar homogéneo sino que se encuentra diseminado en las Ciencias de la Educación, especialmente la psicología de la educación, la historia de la educación y la pedagogía, la evaluación de la educación y/o la planificación de la educación; o formando parte de un tema del programa de la didáctica, o planes y programas parcialmente. Entre los trabajos que dedican estudios especialmente a la disciplina del curriculum, citamos a: BRAVO JAUREGUI, Luis. "Teoría y práctica curricular". Editorial Carhel S.A. Caracas, 1988; VILLARROEL, César. "El curriculum en la educación superior". Editorial Dolvia. Colección Paideia; VARELA DE MACHADO, Carmen (2000) "La concepción curricular en el proyecto educativo. Reflexiones y Propuestas. Revista Cándidus Año 1 - No.10 - Junio / Julio 2000. Esta dificultad epistemológica hace que no podamos determinar de manera concluyente la construcción del campo intelectual del currículum en sí misma, sino decantándolo de las Ciencias de la Educación. En efecto, las ideas que cimentaron el paradigma neoliberal y su impacto en el curriculum emergieron de manera concomitante con el desarrollo del paradigma científico moderno. Hay consenso en establecer que fue en el proceso histórico que va de 1950 a 1958 (Freites, 1989) cuando 
se inició el llamado proceso de institucionalización de la ciencia venezolana. Como parte integral de ese proceso, el personal científico de muchos organismos dedicados al quehacer investigativo, de desarrollo y académico, se reunieron para formar asociaciones gremiales dedicadas a la defensa de los intereses meramente institucionales. (Requena, 2011, p. 19).

De hecho las instituciones que se fueron consolidando así lo certifican; el Instituto Venezolano de Investigaciones Neurológicas (IVINC) que fue fundado en 1954, allí se desarrolló por primera vez tecnología nuclear en América Latina, al instalarse el primer y único reactor nuclear venezolano, siendo el científico Humberto Fernández Moran el mentor y patriarca; en 1959, Marcel Roche funda el IVIC, y amplia el campo de las investigaciones neurológicas a cinco áreas: Biología, Medicina, Física, Matemática, y Química. EI CONICIT fue creado con la Ley del Consejo Nacional de Investigaciones Científicas en 1967, y en opinión de Humberto Ruiz, el "beneficio más evidente de la actividad del CONICIT ha sido que, con sus programas, ha propiciado la reflexión sobre la problemática de la ciencia y la tecnología." (Ruiz, 1997, p. 88)

El momento político iniciado en 1958 empalma con la emergencia de los postulados de la Organización de las Naciones Unidas para la Educación, la Ciencia y la Cultura (en inglés, UNESCO) sobre la planificación, pero también gracias al presidente Rómulo Betancourt que se hizo gran amigo del presiente norteamericano John F. Kennedy, aliado de su tesis Alianza para el Progreso. Durante este proceso se creó la Oficina Central de Coordinación y Planificación de la Presidencia de la República (CORDIPLAN-1958), el Centro de Estudios del Desarrollo (CENDES) en 1960. Centros dinamizadores para impulsar las políticas desarrollistas y los proyectos vinculados a los ejes gubernamentales.

En 1961, en la Carta de Punta del Este-Uruguay se reconoció la Planificación como instrumento fundamental para movilizar los recursos nacionales; y el 5 de agosto de 1961 se reunieron las 21 Repúblicas Americanas en la Conferencia de Punta del Este Uruguay, y entra en escena el plan reformista liderado por EE.UU., con gran parte de los líderes de América Latina; un plan con impacto en la integración regional en lo económico, la estabilidad democrática y el bienestar social para Latinoamérica. Los acuerdos suscritos en la Conferencia, se fundaban en los supuestos teóricos de Walt Rostow y Max Millikan, ambos del Center for International Studies (CENIS) del MIT (Massachusetts Institute of Technology). Se consideraba estimular en los países periféricos y rezagados a la reproducción de etapas del desarrollo social, copiando los modelos de los países desarrollados. La modernización no implicaba sólo un proyecto político e ideológico sino un impacto en lo académico, por tanto, en las ideas del curriculum. $Y$ aquí descansa nuestra tesis en el presente estudio.

Luego, en 1962, en Santia $\neg$ go de Chile, tuvo lugar la conferencia sobre Educación y Desarrollo Económico; en 1966 se convocó en Buenos Aires la conferencia de Ministros de educación y Ministros encarga $\neg$ dos de Planeamiento Económico de los países de América Latina con la tesis "la educación como inversión económica rentable"; en 1967 se reunieron los Presidentes de América en Punta del Este y acuerdan mejorar los sistemas de adminis $\neg$ tración y planificación de la educación; en 1968, la O.N.U., hace suyos los planteamientos de la C.E.P.A.L., y publica Educación, Recursos Humanos y desarrollo en América Latina; en 1970, el Ministro de Educación de Venezuela, Hernández Carabaño (Hernández, 1971), junto a sus colegas del Pacto Andino firman el Convenio "Andrés Bello". 
Así nació la tesis de la Alianza para el Progreso, idea del Presidente John F. Kennedy, con el fin de promover el plan de ayuda económica en América Latina y contrarrestar la influencia del comunismo. Lo inspiraban dos puntos importantes, la política de la Buena Vecindad de Roosevelt, y evitar una segunda Cuba. En la propuesta intervinieron representantes de la sociedad americana y latinoamericana, especialmente de la Cepal, donde

\begin{abstract}
participaron jóvenes académicos, como: Lincoln Gordon, de Harvard, quien había trabajado en el Plan Marshall, Robert Alexander, de Rutgers University, estudioso de la izquierda democrática en Latinoamérica, Arthur Whitaker, de Pennsylvania, historiador especializado en América Latina. Luego se incorporó el experimentado Adolf Berle. En la elaboración del programa de la Alianza, influyo el optimismo universitario de sus redactores, la experiencia del Plan Marshall, y las metas que se habían propuesto los economistas latinoamericanos de la Cepal, Comisión Económica para América Latina, creada a instancias de la ONU en 1948, en la que intervinieron de forma destacada, el argentino Raúl Prebisch, el venezolano José Antonio Mayobre y el chileno Felipe Herrera. (Ramos \& Castro, 2014, p. 98).
\end{abstract}

Otro de los documentos pioneros importante de este proceso es La Carta de Bogotá, reunidos entre el 5 y el 13 de septiembre de 1960 en la capital colombiana, que fue conformada por 21 representantes de las 21 repúblicas americanas que fue conocido como el "comité de los 21" para debatir acerca las problemáticas sociales y económicas del continente. Se constituyó en el antecedente inmediato más importante de lo que más tarde Kennedy designaría, Alianza para el Progreso.

También el llamado Informe Atcon en materia educativa tiene su objetivo a nivel de la Educación Superior, como plan norteamericano para los países latinoamericanos tendrá su impacto en el curriculum; obviamente contando con las complicidades del presidente Rafael Caldera, y que proponía la "aplicación de una política modernizadora educativa orientada hacia el modelo de educación superior norteamericano (Plan Atcon, Plan Básico para Educación Superior, Plan de Desarrollo del Banco Interamericano de Desarrollo)." (Acevedo, 2017, p. 18) El plan modelizador mediante el cual se pretendía trazar el derrotero de la educación superior en Venezuela a partir de referentes universitarios estadounidenses, lo cual incendió las casas de estudios superiores, provocando la radicalización de la lucha antiimperialista en el discurso estudiantil; que llevó incluso al allanamiento de la Universidad Central de Venezuela, y el estallido de la Renovación Universitaria.

En la llamada Gran Venezuela o "Venezuela Saudita" durante la primera presidencia de Carlos Andrés Pérez (1974) el supuesto fundamental fue cerrar el triángulo entre la concepción de la ciencia, el sector empresarial y el Estado, de acuerdo con el esquema del triángulo de Sábato. Se siguió la tesis de la Alianza para el Progreso según la cual el atraso científico y tecnológico explicaba el subdesarrollo de nuestro país. La presidencia de Carlos Andrés Pérez (19731978) también continuara por otras vías ese modelo de acercamiento a los países hegemónicos, para lo cual se creó en 1975 las becas gran Mariscal de Ayacucho; una institución venezolana creada por el ministro de Cordiplan, con el ministro Gumersindo Rodríguez, mediante Decreto Ejecutivo $N^{\circ} 1.000$ de fecha 1 de julio de 1975, emanado de la Presidencia de la República, bajo el mandato del 
Presidente Carlos Andrés Pérez. En parte, una generación formada en los grandes centros de saber mundial, a su retorno al país, permitió acercar la producción de conocimiento con los países de punta. Pero no todos regresaron, muchos pasaron a formar parte de la fuga de talentos, de la descapitalización intelectual;

\begin{abstract}
Sin duda, corresponde al sector de Ciencia y Tecnología dar la mayor contribución para reducir la brecha que se acrecienta entre los países desarrollados y subdesarrollados, pero la apropiación de talentos por el Norte industrializado atenta contra nuestro progreso. Según la UNCTAD, 825.000 profesionales procedentes de países tercermundistas emigraron entre 1960 y 1987 hacia USA. A finales del siglo XX cerca de 75\% de los científicos e ingenieros que trabajaban en Estados Unidos eran nativos de países pobres, y por si fuera poco, los estímulos para incorporar más profesionales extranjeros se refuerzan (...) el Congreso de Estados Unidos decidió agregar 20.000 visas H1B a las 65.000 ya previstas, para "evitar la fuga de talentos" de inmigrantes especializados, graduados o no en ese país (...) Venezuela no escapa de esta situación. (Montilla, Últimas Noticias, $2 / 12$ / 2004, p. 17).
\end{abstract}

Debo agregar, en honor a la verdad que también muchos de los talentos formados en el exterior, al regresar al país no encontraron camino fértil para reinsertarse en el aparato productivo. Incluso muchos se quedaron en el país pero en trabajos que en nada tenía que ver con su formación.

Diversos programas contribuyeron a la formación de las generaciones emergentes; la formación de alto nivel de las elites intelectuales que buscan profesionalizar a los jóvenes de las elites privilegiadas en instituciones universitarias de los países desarrollados, como el conocido "Programa Galileo." (León, 1992: p. 33) En el campo de la Educación Básica el Estado al mismo tiempo que privilegia a los sectores pudientes, alimenta los sectores populares con programas de alivio circunstancial, con el apoyo a pequeñas elites, como los Colegios $\mathrm{Fe} \mathrm{y} \mathrm{Alegría.} \mathrm{Frente} \mathrm{a} \mathrm{este} \mathrm{proceso,} \mathrm{alimenta} \mathrm{la} \mathrm{creación} \mathrm{de} \mathrm{la}$ Educación Privada y los Institutos Universitarios Privados, para ir fomentando le proliferación de la privatización de la educación, clara política neoliberal. (Albornoz, 1991).

En la segunda presidencia de Carlos Andrés Pérez (1989-1993) se crearon, por otra parte, mecanismos para la evaluación de los investigadores como el Sistema de Promoción al Investigador SPI, en 1990, sobre la base del modelo mexicano. Lentamente se imponían los valores de la productividad, la calidad, la eficacia y la eficiencia como baremos en la producción de conocimientos, típicos criterios de los modelos neoliberales. Los ministros eran un clan orquestado de neoliberales: Rossen en Educación; Cole, en Agricultura y Cría; Tinoco, en el Banco Central, para no dejar dudas de que las políticas de Estado tenían una sólo dirección.

Las universidades comenzaron a ser presentadas en un ranking nacional en función a esos criterios. Y la educación privada se fue macerando como panacea que podría reemplazar la educación pública con perfiles de rendimiento de excelencia. Las estadísticas de la escolaridad desde mediados de los 80 nos permiten ir demostrando la consolidación del modelo neoliberal, en efecto la deserción escolar en la Educación Básica; 
En 1989 sólo el $89 \%$ de los niños en las edades correspondientes estaban cursando de primero a sexto grado y sólo el $85 \%$ estaba cursando de primero a noveno grado. Sin embargo, sólo el $23 \%$ de las personas entre 15 y 17 años estaban inscritos en los dos últimos años de bachillerato. (Reimers, 1992, p. 16).

La idea era desprestigiar la educación pública en favor de la educación privada, "mientras que sólo $20 \%$ de los niños de las escuelas públicas completa nueve grados, $61 \%$ lo logran en las escuelas privadas." (Reimers, 1992, p. 20).

La crisis tuvo su detonante cuando en 1989, cuando se produjo la llamada crisis del 27 de febrero, "el día que los cerros bajaron", como una medida de protesta por los altos costos de vida a raíz de los acuerdos con el llamado "paquete económico" del presidente Carlos Andrés Pérez. De esa manifestación de descontento nunca se recuperó y luego vendría la asonada militar de 1992, cuando emerge la figura de Hugo Chávez Frías. Lo demás es historia.

En todo caso, la institucionalización de la investigación con la creación de los principales centros de investigación y la promoción de la investigación como única forma de acercarnos al primer mundo deben ser resaltados como algunos de los grandes logros de este proceso. Aun cuando no se formó en Venezuela, el único Premio Nobel venezolano: Baruj Benacerraf, se formó en EEUU y Francia. Marcel Roche, quien fuera el fundador del Instituto Venezolano de Investigaciones Científicas (IVIC) publicó una nota de prensa sobre Baruj Benacerraf, premio nobel en Medicina y Fisiología 1980, en la que alertaba lo difícil que era competir desde el Tercer Mundo para optar a un premio nobel, si se hubiese quedado en Venezuela para hacer carrera académica "hubiera tenido más dificultades en llevar a cabo sus investigaciones. Hubiera sido afectado por los presupuestos para la ciencia que suben y bajan intempestivamente, nuestra nefasta tendencia a cortar la cochina en partes iguales y a favorecer por igual al destacado y al mediocre, nuestro turbulento ambiente social y el omnipotente virus político. (Roche, 1987, p. 208).

Para cerrar esta parte introductoria queremos presentar la importancia de las tendencias japonesas y su impacto del curriculum en Venezuela, entre finales de los años 90 y década del noventa. Casi nunca se ha destacado esa tendencia pero indudablemente que sirvió de acicate para potenciar la lógica neoliberal en la adaptación de los principios empresariales de la gerencia y la administración de las corporaciones japonesas a la administración escolar. Con el auge de la empresa japonesa, se comenzaron a generar revisiones fundamentales en la sociedad occidental, sobre todo en el subsistema de valores y clima organizacional. El giro fundamental se inició con la publicación de sendos libros que registraron los desafíos planteados por el Japón a la industria norteamericana, y obviamente latinoamericano; entre ellos: La Mente del Estratega, el triunfo de los japoneses en el mundo de los negocios (Ohmae Kenichi, 1980), La teoría Z (Ouchi, 1981) y El Arte del Empresario Japonés (Pasccale y Athos, 1981). Más tarde aparecieron Cultura Corporativa (Deal y Kennedy, 1982), En Búsqueda de la Excelencia (Peter y Waterman, 1982), y alcanzarón la cima de esta tendencia Del Caos a la Excelencia (Peters, 1992), Reinventando la Excelencia, (Peters, 1993) y Pasión por la Excelencia (Peters y Austin, 1994). Trabajos que ejercieron gran influencia a través de las tendencias tecnocráticas, porque se comenzó a extrapolar los conceptos del mundo de la Administración y la Gerencia al mundo de la Administración Escolar. En especial a través de los estudios de postgrados, V. Gr: la Maestría en Gerencia Educativa, (Mora, 1994) donde se presentaron los 
autores básicos del mundo empresarial como es el caso Stoner \& Wankel, para hacer la adaptación a la Administración escolar. Lo propio con Philip Kotler, en la gerencia estratégica. La cultura de la excelencia se fundamentó al interno de la comunidad discursiva empresarial. Por lo que fue necesario apoyarse en los autores de la Pedagogía Crítica para contrarrestar esa visión instrumental. Es el caso de McLaren (1989), quien nos aporta categorías para la redefinición de la interpretación neoconservadora de la excelencia académica, que sostiene que la finalidad fundamental de la educación sea la productividad económica, ya que "al definir el éxito académico casi exclusivamente en términos de crear trabajadores cumplidos, productivos y patrióticos, el nuevo programa conservador para una nación resurgente evade cualquier compromiso para formar ciudadanos críticos y comprometidos." (McLaren, 1989, p. 198) La teoría curricular de talante neoconservador se caracteriza por trasladar la lógica del mercado a la escuela, son grupos que están construyendo su identidad con "movimientos de la nueva derecha, movimientos cercanos a las empresas, adalides del neoliberalismo, neoconservadores y fundamentalistas religiosos, más profesionales de la enseñanza que dan cobertura técnica a las demandas de control y medición" (Rodríguez, 1998, p. 164). Como ejemplo de modelos curriculares influenciados por ésta comunidad discursiva podemos citar la reforma de 1988 en Gran Bretaña y lo que se denominaba Primera Ola de reforma en los EEUU, y que fue generalizada con el nombre de Regreso a lo Básico. En Venezuela, enmascarado en el movimiento de las denominadas escuelas eficaces (Báez, 1991), se esconde todo un programa neoconservador, bajo los términos de escuelas ejemplares, eficacia de la escuela, escuelas eficaces y mejora de la escuela, cuando en realidad responden a resultados alterados, manipulados, por los miembros de la institución escolar, con complicidad externa o sin ella, constituyendo la base de acciones innovadoras de optimización en su rendimiento académico; se "pretende encontrar indicadores de la eficacia de las escuelas en términos de rendimiento de los alumnos (...) emplea instrumentos estandarizados, muestras representativas y análisis estadísticos y correlaciones" (Marcelo, 1995, p. 22). Esta tendencia, amparada todavía en el paradigma proceso-producto, presenta el éxito como el proceso de la traducción fidedigna de lo que se enseña, cuando en realidad el acto pedagógico no tiene ningún sentido si no estimula la creatividad; sin la cual es imposible el pensamiento abierto. Los docentes "a menudo caen en la trampa de definir el éxito en simples términos de la exactitud ideológica de lo que enseñan." (McLaren, 1989, p. 270).

Estos libros desplazaron el centro de gravedad de las organizaciones tradicionales. En lugar de manejar las grandes corporaciones como cajas negras para responder a los mercados externos con criterios financieros, las nuevas tendencias se comenzaron a centrar en el lado comportamental de la organización interna, sosteniendo que la diferencia entre organizaciones exitosas y no exitosas estriba en los valores y principios que sirven de fundamento a su organización interna. De allí se incorporó los criterios de la Psicología Social de las Organizaciones al mundo escolar y el curriculum.

\section{El Modelo Eficientista en las políticas de Estado y su impacto en el Curriculum}

El modelo eficientista es la tendencia más cercana al modelo neoliberal por su filosofía y por sus postulados. Particularmente se hace el estudio a partir de la 
influencia de la obra de Tyler. La edición de Tyler que hemos encontrado en los anaqueles de las bibliotecas universitarias y bibliotecas familiares de los docentes es Tyler, Raph W. (1973). Aunque hay muy pocas referencias en la bibliografía de los programas de las escuelas de educación en la década del setenta, si es posible documentarla en los proyectos oficiales y en testimonios de los docentes. En ese sentido, también tendríamos que agregar a los autores que complementan su modelo y que ejercieron influencia en Venezuela, como: Bloom, Mager, Glaser, Carroll; aspecto que podemos constatar con el uso de conceptos introducidos en la escuela, como

\begin{abstract}
el uso de objetivos expresados en términos de conductas observables (Mager,1962), el desarrollo de una tecnología representadas por las pruebas y criterios referenciales (Glasser, 1963), el concepto de master y learning, introducido por Caroll (1963) y Bloom (1968) y finalmente, la introducción en educación de conceptos y técnicas derivadas del campo de la administración y la teoría de las organizaciones, es decir, uso del análisis de sistemas y la toma de decisiones en la evaluación de programas educacionales. (Salcedo, 1980, pp 88-89).
\end{abstract}

En las políticas educativas del Estado venezolano, el eficientismo social encuentra en la reforma educativa una oportunidad para presentar sus postulados. En efecto, El 13 de agosto de 1969, se promulgó el Decreto 120, y se produce la nueva Reforma Educativa introduciendo el Ciclo Básico Común, y el Ciclo Diversificado en sustitución de la Educación Técnica. Ciertamente la educación técnica había sido una propuesta de la Ley de Educación de 1940, en época del ministro de educación Arturo Uslar Pietri, habiendo crecido "de apenas 783 (1951) a (...) 28.022 (1966)." (Alvaray, Carvajal, et Al, 1977, p. 33) La idea fundamental era promover la educación para el trabajo, inicialmente con las llamadas Áreas de Exploración, luego con la Reforma de 1980, la Educación Básica incorpora por Resolución en 1986 la Educación para el Trabajo. Nacarid Rodríguez realizó un análisis del diseño curricular tomando como fuentes de primera mano el Normativo, el Plan de Estudios y los Programas del Área. Dedica igualmente un estudio a los fundamentos del currículum, y los define como los conocimientos teórico - prácticos de la filosofía, la psicología, la sociología y la pedagogía que sirven de base al desarrollo del currículum; presentando un estudio de las bases psicológicas en donde manifiesta la dependencia conductista, la emergencia de la teoría cognitiva, el humanismo y la psicología. Por su parte, la profesora Aurora Lacueva realizó un interesante trabajo en donde analiza los programas de Educación Básica, manifestando que "los programas del ensayo de educación básica (1981) en adelante presentaron cambios importantes en relación a los programas anteriores del nivel primario. Establecieron en su sección introductoria que eran instrumentos flexibles y semi-elaborados_orientados a la labor docente_ que permitían y hasta requerían de su enriquecimiento a nivel local (...)" (Rodríguez, 1989, p. 35).

El paradigma planificador-eficientista oficialmente está refrendado en el IV y V Plan de la Nación, siendo sus principales impulsores los Ministros de Educación Hernández Carabaño (1969-1971) y Luis Manuel Peñalver (1974-1977). En el IV Plan de la Nación (1970-1974) se expresa la teoría curricular de los planes y programas de la educa $\neg$ ción, que podemos inferir de las siguientes categorías: 1. La organiza $\neg$ ción racional del trabajo para mayor eficiencia en el uso de los recursos humanos; 2. La actualización de los contenidos educacionales; 3 . El nuevo régimen de Educación Media, con un Ciclo Básico Común de tres años, un

History of Education in Latin America - HistELA, v. 3, e19924, 2020, p. 10 de 24 
Ciclo Diversificado de dos años y un ciclo diversificado profesional de tres años; 4. La organización de la Oficina Regional de Educa $\neg$ ción; 5 . Y el régimen especial de evaluación. En el V Plan de la Nación (1976-1980) sigue el mismo proyecto tecnocrático, expresado fundamentalmente en la llamada "Revolución Educativa", que tenía entre sus objetivos la capitalización del hombre como fuerza de trabajo que permitiera modernizar el proceso productivo y lograr los objetivos de expansión económica e incremento de la productividad. La educación se constituye en el eje para el desarrollo socio-económico del país, teniendo como perfil formativo la consolidación del recurso humano, eficiente y eficaz.

Con la decadencia de la pedagogía progresista de Dewey, eclipsada por la emergencia decisiva del eficientismo social la educación buscó modelarse sobre las base de las ciencias duras, simulando rigurosidad científica a partir de la aplicación de los llamados "testing", o pruebas objetivas para todo; en donde se combinaban los criterios del conductismo y la administración científica. Este modelo ha recibido críticas como las expresadas por Raymond Callahan, Education and the cult of efficiency (1962), uno de los críticos más acérrimos al señalar que "los educadores pasaron de ser filósofos a ser "mecánicos" de la educación y capitularon ante los principios de la administración científica (Tanner y Tanner, 1975)." (García, 1995, p. 59).

La teoría del Capital Humano sirvió para instrumentalizar la educación, cosificar al alumno y mediatizar los procesos de reflexión y cam $\neg$ bio; al respecto agrega Gustavo Villamizar, profesor de la Universidad de Los Andes-Táchira, quien nos testimonia su formación en el programa del eficientismo social en los siguientes términos:

todo ese paquete conocido como tecnología Educativa, llegó a nuesᄀtras tierras inicialmente con la reforma de Hernández Carabaño durante el primer período presidencial de Rafael Caldera, afinada posteriormente por la "Revolución Educatiᄀva" de Luis Manuel Peñalver en el primer gobierno de Carlos Andrés Pérez y más tarde, se incorporan sus postulados generales a la base conceptual de la Ley Orgánica de Educaᄀción de 1980. A partir de entonces nos hemos visto colmados por " objetivos en términos de conducta observable", "objetivos generales y específicos", "textos didácticos", "evaluación objetiva", "exámenes de marcar", "diseño instruccional", "recursos para el aprendizaje", "facili-tadores", "Situaciones de aprendizaje", e incluso nuevas maneras de llamar a los seres humanos que participan en el proceso incluyéndolos en la categoría de "recurso" y algu $\neg$ nos abusadores hasta llegan a designarlos como insumos. (Villamizar, 1995, p. 9).

A estas categorías habría que agregarle la concepción del currículum cerrado, caracterizado por la evaluación para el control, la planificación por objetivos, el control del plan de clases (plan trimestral y plan anual), y el control del docente y las supervisiones de clases.

La tesis del capital humano:

percibe que la teoría del capital humano, se manifiesta tanto en nivel macro cuanto micro, apuntando la educación como una inversión, como una posibilidad de acumular capital, de generar lucros. Sin embargo, esta sociedad entre educación y mercado de trabajo que prometía el desarrollo económico por medio de oportunidades de empleabilidad se vio ofuscada con la crisis del capitalismo en la década de 1970. En detrimento, en la tentativa de reestructurar los embates de la crisis, se aumentó la privatización de los 
bienes públicos a fin de movilizar el capital financiero y, consecuentemente, estabilizar el mercado de trabajo y las posibilidades de empleo. (Herrera, 2015, p.16958).

De esa manera, se construyó un aparato crítico que apostaba más a los intereses del mercado y no tanto a los del Estado, la meritocracia como valor social impulsaba la movilidad social;

lo que marca la educación como factor económico en vías a su homogeneización en una tendencia tecnocrática de enseñanza-aprendizaje, y, posteriormente, imposición moral de comprender el concepto de igualdad al nivel de equidad, determinando las relaciones educativas, a la meritocracía, como expresión de la distribución desigual y excluyente a partir de las competencias de los individuos. (Herrera, 2015).

La meritocracia obviamente favorecía a los mejor dotados intelectualmente, a los que mejores opciones habían tenido para formarse; era una forma de legitimar la exclusión de los sectores populares. Estas son las paradojas en las cuales se incurrió en la educación venezolana que propició una desigualdad social, al Estado invertir más pero favoreciendo a los que más tenían, "las dos terceras partes de los estudiantes de las universidades públicas provienen del veinte por ciento de familias que tiene el nivel más alto del ingreso del país y que en esas universidades impera la gratuidad absoluta de matrícula, determina que ese veinte por ciento de población con más recursos reciba el cuarenta por ciento de la inversión educativa total." (Carvajal, Leonardo, 1998: 143) Los menos favorecidos eran los que menos recibían, el $40 \%$ de las familias en peor situación socio-económica, recibían menos del 30\% del gasto público en educación. (Navarro, 1991) Así se fraguó un descontento histórico que llevó a la sociedad venezolana a pensar en las superadas visiones mesiánicas del siglo XIX, pero que en la historia lenta anidan en el inconsciente colectivo; sobre esa base se construyó el mesianismo de Hugo Rafael Chávez Frías.

Las ideas neoliberales revestidas de meritocracia fueron impulsadas en a través de las Misiones de la OEA (ARANGO, 1975) y la UNESCO (Unesco, 1974), en conjunto con el Ministerio de Educación de Venezuela, a ellas se sumaron algunas universidades, fundamentalmente las que tenían un perfil tecnológico, entre las universidades públicas destacamos a la Universidad Simón Bolívar de Caracas; y entre las universidades privadas, como la UCAB, la Universidad Tecnológica del Centro, y la Universidad Belloso Chacín, y algunas universidades regionales, como la Universidad Nacional Experimental del Táchira, en donde se fueron realizando Seminarios para reformar el Curriculum con perfiles hacia la visión tecnocrática. Los docentes poco a poco se vieron motivados a realizar estudios de cuarto y quinto nivel en universidades norteamericanas e inglesas; el ejemplo más reconocido fue el profesor Manuel Castro Pereira, quien realizó estudios en la Universidad de Burmgham (Inglaterra) sobre evaluación curricular, y a su regreso desarrolló el modelo del curriculum sistémico. Cfr. Castro, M (1981) Módulo de Apoyo para el Curso de Diseño Curricular. Lecturas Básicas. Compendio. Maracay. Castro, M. (1982) Diseño de Instrucción. Módulo de Apoyo. Caracas. Castro, M. (1984) Evaluación Curricular. Aproximación a un Modelo. Ediciones Atal, S.R.L. Caracas. Castro, M (1975) Currículum. Texto Básico para una Auto-instrucción. Caracas. El programa de becas de la Fundación Gran Mariscal de Ayacucho, institución creada en el primer gobierno de Carlos Andrés 
Pérez en 1974, fue una institución básica para la formación de talentos en el exterior.

El eficientismo racionalizó al máximo los fundamentos del currículum haciendo descansar las bases científicas de la teoría del curriculum fuera de la pedagogía, en concreto: la filosofía, la psicología, la economía, y la antropología. El modelo tecnológico de producción por antonomasia diferenció entre bases y fundamentos del currículum, las bases estaban referidas a las condiciones económicas, sociales, políticas, culturales; y los fundamentos, estaban influenciados por las bases y se limitarían a lo psicológico, sociológico, antropológico y pedagógico. Para este enfoque educar es un proceso para la adquisición de destrezas y técnicas.

La década del ochenta siguió influenciada por el paradigma eficientista y la Ley Orgánica de Educación (1980) recoge su espíritu:

las funciones de acuerdo a lo establecido por el Ministerio de Educación (1980), en el artículo 107 y por la pertinencia de éstas en el cumplimiento de la acción supervisora tales como: planificar, orientar, dirigir, ejecutar, coordinar, supervisar y evaluar; cada una tiene como finalidad, verificar la ejecución de los objetivos y fines de la educación en forma participativa, integral, cooperativa, competitiva y efectiva. (Mogollón, 2004, p. 36).

El plan neoliberal encuentra aliados importantes para demostrar que los aportes económicos con valores neoliberales en los sectores populares puede dar resultados significativos, como el Proyecto de las Escuelas Eficaces en Venezuela dirigido por Mariano Herrera (1996), en 1991 realizó un estudio en las Escuelas de Fe y Alegría para determinar por qué siendo unas escuelas para sectores resilientes tienen un alto índice de éxito escolar. En la Asamblea Nacional de Educación expuso los lineamientos de la pedagogía eficaz, los cuales fueron tenidos en cuenta en algunos modelos escolares; para Mariano Herrera el modelo de Vigostsky es más importante que el de Piaget, porque pone el acento en el aprendizaje. (Herrera, 1998) Por su parte, Víctor Guedez (2005) también nos aporta reflexiones sobre currículum y calidad, sobre todo vinculados a la gerencia educativa.

En materia de evaluación educativa se importan los criterios de los más connotados especialistas norteamericanos, justamente de profesores que se fueron a formar en EEUU. Así llegan los criterios de los profesores Castro, 1982). En el caso de Castro Pereira lo despliega a través de un plan de evaluación curricular, conocido como "Modelo Institucional de Evaluación Curricular" (Castro, 1984), un modelo influenciado por la teoría de la evaluación curricular de Stufflebeam (1971), Bayley, (1976), Kaufman (1973), Stake (1975); y tuvo una marcada demanda.

Inmediatamente fue acogido por la Academia Militar de Venezuela, la Universidad Simón Bolívar, el Instituto Universitario Santa Rosa de Lima, el Colegio Universitario de Los Teques Cecilio Acosta, la Universidad Nacional Abierta y la Universidad de Carabobo, en Valencia. Debo agregar que en 19891989 fui delegado como Sub-Director Académico del Instituto Universitario Eclesiástico "Santo Tomás de Aquino" para ser formado en estos criterios en el curso que dictó el Dr. Castro Pereira en el IUT Región Los Andes, en San Cristóbal. 
La historia de las cátedras es un proyecto que requiere ser analizado para evidenciar el verdadero impacto de las teorías del curriculum; al respecto comenta Goodson (2000) "Tendría que desarrollarse un campo de estudio que pusiera las asignaturas en el centro de la investigación. El punto de partida sería buscar los orígenes de la construcción social que representa la enseñanza y actualizar las razones por las que emergen y se institucionalizan las asignaturas escolares." (Goodson, 2000, p. 49) En ese sentido, presentaremos algunos ejemplos desarrollados en las universidades venezolanas respecto a la formación en el área de curriculum.

En la Universidad de Los Andes, destacamos el trabajo del profesor Gabriel Armando Carvajal Mantilla, el profesor Gabriel Armando Carvajal Mantilla es profesor de la Universidad de Los Andes, egresado de la Universidad Católica Andrés Bello extensión Táchira (UCABET), Magister en Administración Educacional (1979) en la Universidad del Valle (Colombia), becado por la Fundación Gran Mariscal de Ayacucho. Fue fundador del Liceo "Antonio Sánchez Pacheco" en Santa Ana, estado Trujillo (1973), consejero de la Zona Educativa del estado Trujillo en representación del NURR-Trujillo para la implementación del curriculum de Educación Básica. Es Carvajal quien a través del programa PREXFORDO (diseño curricular para la formación del docente en servicio a nivel de la Educación Superior, elaborado por la UPEL y el M E.) sirvió como programa de formación docente pionero, coordinado en Trujillo. Este es el antecedente para que las universidades asumieran también la formación de docentes, en este caso, la Universidad de Los Andes (ULA) NURR- Trujillo, cuyos contenidos fueron publicados en forma mimeografiada en un Manual de Educación Básica. (CARVAJAL, 1983) Estos trabajos fueron la base para la creación de la carrera de Educación Básica Integral en la ULA-Nurr Trujillo. Luego, vendría el profesor Carvajal a la ULA Táchira (1994) para participar en el desarrollo de la carrera de Educación Básica Integral; el profesor Carvajal incorporó las asignaturas de Extensión Universitaria. Esta carrera sirvió como centro piloto para la formación de los docentes en servicio y estudiantes de nuevo ingreso.

Los programas de postgrado en Maestría del Curriculum o con líneas de investigación sobre Curriculum, los encontramos en universidades públicas (Universidad del Zulia, Universidad de Carabobo, Universidad de Oriente, Universidad de Los Andes) pero también en universidades privadas (Universidad Bicentenaria de Aragua); el Doctorado en Educación (UCLA-UNEXPO-UPEL-IPB) con la línea de investigación sobre Curriculum. Destacamos al respecto el proyecto del Dr. Reinaldo Rojas, con "la Línea de Investigación Pedagogía, Currículo y Formación Docente, iniciada en 2004 en el Programa Interinstitucional de Doctorado en Educación UCLA-UNEXPO-UPEL, con sede en Barquisimeto, con Tesis Doctorales en Educación (con énfasis en Currículum), aprobadas y cuyos resultados parciales han sido presentados en diversos eventos nacionales e internacionales." (Rojas, 2009, p. 125) Entre las que citamos: Abraham Toro (2009) quien certifica la presencia del discurso Cepalista, el discurso tecnocrático y las tesis del desarrollismo en la Universidad de Carabobo; siguiendo a Iván Hurtado León (1997) "las universidades públicas y privadas, se convierten entonces en instituciones que deben crear las condiciones para el despliegue de las actividades que genera esa dinámica desarrollista modernizadora y, con ello, profundizar los rasgos capitalistas de la sociedad venezolana." (Toro, 2009, p. 102-103).

Universidad del Zulia (LUZ) desarrolló la Maestría en Educación, Mención Currículo, proyecta su perfil para el diseño, gestión, evaluación e investigación 
curricular. El currículo como un proceso transformador que debe responder a las exigencias de cambio para satisfacer las necesidades sociales relativas a la formación del mundo actual. En su Visión, el programa presenta está adscrito a la División de Estudios para Graduados de la Facultad de Humanidades y Educación de LUZ, tiene por objetivo ofrecer formación de elevado nivel en esta área, basándose en el estudio sistemático y profundo de los procesos educativocurriculares, para lograr el dominio y aplicación de diferentes métodos de investigación, a fin de interpretar, transformar y evaluar el currículo en los distintos niveles del sistema educativo. El Comité Académico de la Maestría está integrado por las siguientes profesoras: Dra. Hermelinda Camacho - Coordinadora, Dra. Alicia Inciarte, Dra. Noraida Marcano, Dra. Liliana Canquiz e Dra. Itala Paredes.

En la Universidad de Oriente, el profesor José Sánchez Carreño, analiza la práctica curricular en las instituciones universitarias; señalando que es

un modelo de formación caracterizado por la presencia de diseños curriculares fragmentados, con programas enciclopedistas que privilegian la simple adquisición de información y la acumulación de contenidos reduccionistas que ignoran la complejidad actual. Frente a estos planteamientos, la universidad reclama un currículo que garantice la elaboración conjunta del saber, que tome en cuenta la experiencia de los docentes, el mundo de vida de los estudiantes y la representación social de la realidad. Para ello, es necesario articular propuestas que enfaticen la confluencia, interacción e integración de saberes, que revelen nuevas interrelaciones y perspectivas para abordar y comprender el mundo actual caracterizado por lo complejo, lo diverso, lo múltiple, lo sensible. (Sánchez, 2014, p. 68).

Aunque el autor propone un acercamiento a las visiones heterodoxas que se vinculan con la versiones con los enfoque del curriculum emergente, se queda sólo en la formulación formal de las teoría que pudieran influir pero no dice cómo hacerlo. En cuanto a las teorías que han alimentado la etapa neoliberal no dice nada, son trabajos que adolecen de las visiones que Kliebard (1986) cataloga como la versión del curriculum ahistórico.

A nivel de las autoridades universitarias destacamos la Comisión Nacional de Currículo (CNC), cuya idea nace del Núcleo de Vicerrectores Académicos de las universidades venezolanas, y aunque su labor es fundamentalmente técnicoasesora a través del contacto directo con las Comisiones Curriculares de cada institución, cumplió una labor de formación y difusión. Fue creada en 1986, y en 1992 se propuso la celebración bienal de un evento curricular a objeto de reunir a especialistas y docentes para intercambiar experiencias en la aplicación de los parámetros-criterios sugeridos, y plantear nuevos problemas, desafíos, retos e innovaciones de las diferentes instituciones de Educación Superior. Esta mirada instrumental siguió alimentando lo que Ángel Díaz Barriga (1989) denomina la calidad líquida, lo cual se puede evidenciar en las Reuniones Nacionales de Currículo en la Educación Superior Venezolana los años 1993 (ULA, Mérida), 1995 (LUZ, Maracaibo), 1997 (UC, Valencia), 1999 (UDO, Cumaná), 2002 (UCV, Caracas), entre otros.

Otros proyectos alternativos sirvieron para reforzar la discusión entre la didáctica y el curriculum, entre ellos: Herrera y López (1993) El Proyecto Plantel: Características, fases, herramientas, el cual fue oficializado en el diseño del curriculum Básico Nacional de 1997. Reflexiones similares fueron hechas por 
Álvarez, Duplá y Estrada (1995) Doce propuestas educativas para Venezuela, y el grupo FÉ Y ALEGRÍA.

La construcción de un espacio y/o comunidad intelectual del currículum en Venezuela no ha sido fácil, pero a manera de síntesis podríamos discriminar en tres las tendencias del pensamiento curricular en Venezuela: a. Las tendencias del diseño curricular centrado en las didáctica general; b. la centrada en las didácticas especiales; y c. las centradas en la tradición de las disciplinas. El desarrollo teórico ha sido desigual, en tanto que algunas tienen mayor impacto en el mundo académico. Una evidencia de ese trabajo lo encontramos en el Thesaurus Curricular Universitario. (Becerra, 2004)

El último de los aportes en materia del Curriculum hasta 1998 fue la creación de la Comisión Curriculum Básico Nacional (CBN-1997), la cual cumplió una labor magistral en la proyección y estudio del curriculum en Venezuela. La reforma del Estado venezolano impulsada por la Comisión Presidencial parta la Reforma del Estado (COPRE) replanteó la política educativa nacional sobre la base de los documentos y diagnósticos efectuados en el país por los entes nacionales e internacionales, entre los que cabe citar: $\bullet E l$ informe de la Comisión Presidencial para el Estudio del Proyecto Educativo Nacional (1986); •El diagnóstico del Banco Mundial (1992); - La Reforma Educativa: Una Prioridad Nacional. (1994); El Plan de Acción del Ministerio de Educación (1995).

Estos esfuerzos permitieron que a mediados de la década de los 90 se hiciera una profunda reforma en el sistema educativo venezolano. Luego que el ministro de educación Antonio Luis Cárdenas anunciara que la educación venezolana era un fraude (Cárdenas, 1998) a raíz del bajo nivel académico, se propuso tres líneas estratégicas: 1. Dignificación de la labor docente; 2. Los Proyectos Pedagógicos Plantel; y 3. Infraestructura y dotación de medios didácticos. Norma Odreman lideró esos cambios y los materializó en el CBN, a través de los Proyectos Pedagógicos de Plantel y de Aula, mediante los cuales se concretan los procesos de reflexión sobre la práctica educativa; la adecuación progresiva de los contenidos de enseñanza; las experiencias significativas y actividades didácticas influenciados por la concepción constructivista del aprendizaje y de la intervención pedagógica. Las teorías del curriculum que nutren al CBN son fundamentalmente el Humanismo; la Teoría Genética de Jean Piaget; la Teoría Sociocultural de los Procesos Superiores de Vigotsky; la Teoría del Aprendizaje Significativo planteada por Ausubel; la Teoría del Procesamiento de la Información; las Teorías Neurofisiológicas y el Constructivismo.

\section{La postmodernidad en el curriculum basico nacional}

En Venezuela la tesis postmoderna no fue recibida pasivamente, los grupos académicos (CIPOST-UCV, Venezuela; Taller de Estudios Epistemológicos, ULATáchira, Grupo de Historia de las Mentalidades-ULA-Táchira; HEDURE-ULATáchira han realizado una amplia productividad para discutir el tema. Nuestra contribución en el desarrollo de la teoría del curriculum postmoderna se inició en 1992, y desde entonces desarrollamos la línea de investigación por 20 años, evidenciada en la producción teórica la cual ha sido llevada a las escuelas, liceos y universidades en todo el país. El principal mentor del postmodernismo en Venezuela fue el sociólogo, Rigoberto Lanz. De él, recibimos los primeros trabajos en 1989, y citamos algunos: LANZ, Rigoberto (1989) Repensar el Método. Rev. Anthropos, Vol. 149, Caracas. Venezuela. (1992) El pensamiento social hoy, 
crítica de la Razón Académica. Tropykos, Caracas. Venezuela. (1993) El discurso posmoderno: crítica de la Razón escéptica. Caracas: U.C.V. (1994) El Malestar de la Política. Mérida: ULA. (1996). Lo que el fin de la política quiere decir. Rev. Relea, No. 1, julio. Caracas. Venezuela. UGAS F. Gabriel. (1998) Paradojas de la Ignorancia Educada. TAPECS. Táchira. Venezuela.

Este trabajo se desplegó desde la Coordinación de Extensión a cargo de Gabriel A. Carvajal M., (1996-1999), y la Unidad de Asistencia a la Comunidad donde se editaron varios artículos y libros que sirvieron de sustento teórico a los cursos de implementación de las teorías postmodernas para los docentes en servicio. Este proyecto motivó la fundación de las Casas Culturales Universitarias de la Universidad de Los Andes en tres municipios (Jáuregui, Sucre y Urdaneta) del estado Táchira, con el apoyo de Román Hernández (Decano Vicerrector), y de Eduardo Zuleta (Coordinador General de Cultura y Extensión de la ULA). Incluso a nivel internacional ha sido presentada en congresos y eventos relativos a la educación y el curriculum, en Tarragona-España; Popayán-Cauca, Colombia; y Tunja- Boyacá, Colombia. Nuestra contribución en el desarrollo de la teoría curricular postmoderna se inició en 1992, con el trabajo: MORA GARCÍA, Pascual (1992) ¿Educar en la Postmodernidad? Aproximación a una filosofía educativa para la Educación Básica) ; luego en la tesis de maestría (1994) presentamos el tema: MORA GARCÍA, Pascual (1994) "Gerencia Educativa Postmoderna en el contexto de las Universidades del Táchira." En 1996, publicamos: MORA GARCÍA, Pascual (1996) Del fin de la historia la postmodernidad; en 1997, MORA GARCíA, Pascual (1997) La Escuela del Día de Después. En el año 2000, presentamos la conferencia inaugural de la II cohorte 2000-2003 del Programa Interinstitucional de Doctorado (PIDE) UCLA, UNEXPO, UPEL, (Barquisimeto) y la conferencia fue publicada en los Cuadernos del Doctorado: MORA GARCíA, Pascual (2000) Universidad, Currículum y Postmodernidad Crítica (2000). Ese mismo año defendimos la Tesina Doctoral del programa de Innovación y Sistema Educativo de la Universidad Rovira i Virgili, Tarragona-España, donde se incorporaron 5 capítulos relativos al tema; luego la reseña MORA GARCÍA, Pascual (2000) “¿Existe un currículum postmoderno?” en la Revista Universitas Tarraconensis, Año XXIV, III época, p. 166; y sobre el tema Gerencia y Curriculum: MORA GARCÍA, Pascual (2001) La gerencia y educación postmoderna crítica. CDCHT- ULA. Mérida. En el 2004, se publicó el artículo "El currículum como historia social (Aproximación a la historia del currículum en Venezuela)" en Rev. Teoría y Didáctica de las Ciencias Sociales. Enero-diciembre, № 9, 2004. pp. 49-74. www.saber.ula.ve/Revista de Teoría y Didáctica de Las Ciencias Sociales. En el DLAE se encuentran las siguientes entradas del autor; veamos: MORA GARCÍA, J. Pascual. (2007): "Postmodernidad-Educación," en: Bravo, L. (Coord) diccionario latinoamericano de educación (DLAE). Caracas, UCV-Fondo Editorial de la Fundación Gran Mariscal de Ayacucho. ISBN 980-002099-3 Fuente: http://www.ucv.ve/eus/eus1.htm Igualmente: "Paradoja de ICARO" "Postmodernidad: Isla o Continente", "Prácticas educativas y pedagógicas en/desde la postmodernidad", "Repedagogización de la vida", "Saber pansófico, El Adios", "Saberes hipertexto." "Alumnos postmodernos." "Androgínia postmoderna." "Aula heterogénea." "Epifanía postmoderna." Escuela del día de después." "Fatiga del método científico en las Ciencias Sociales." "Generación de los niños mimados de la historia." y "Maestros postmodernos."

Oficialmente a nivel del Ministerio de Educación de Venezuela la influencia de la teoría postmoderna se reconoce en el Currículo Básico Nacional (1997), (MINISTERIO DE EDUCACIÓN DE VENEZUELA (1997): al señalar: "la escuela como órgano social para adecuarse a las exigencias de la sociedad postmoderna, 
debe asumir el reto colaborando con la familia y la comunidad." (CBN, 1997: p. 28) Específicamente las características del curriculum postmoderno se presentan en las categorías acerca del curriculum postmoderno, formando parte de la base filosófica; veamos algunas: 1. Curriculum ecológico: "Para ir hacia la construcción de ese conocimiento desde la perspectiva ecológica, este plantea la sustitución del análisis sistemático de las actividades cognitivas (que sólo permite abordar el conocimiento con el uso de inferencias formales)" (p. 28); 2. Pensamiento complejo. "Para Morin un conocimiento complejo, sea éste científico, filosófico, práctico o artístico, debe ser evaluado a partir de la conjunción entre teoría y método (queda entendida en esta interrelación la aplicación). El método para construir el conocimiento retoma la relatividad de la verdad afirmando que el mundo, sus problemas y naturaleza cambian y con ellos el conocimiento humano." (p. 28).

La discusión en torno a la teoría del curriculum postmoderna se remonta a los trabajos de Toulmin, 1982; Gough, 1989; Doll, 1989; Slaughter, 1989; y Molnar, 1992; pero las tendencias del curriculum postmoderno nos la ofrece Estebaranz (1994): "hemos encontrado dos grupos fundamentales de teóricos que se replantean la teoría del curriculum: Los preocupados por definir el mundo postmoderno y el que le corresponde (Gough, 1989; Doll, 1989; Slaughter, 1989), y otros autores procedentes del grupo radical (radical caucus, Molnar, 1992) más preocupados por la distancia tan grande entre la teoría y la práctica, y la poca influencia que ha tenido para el cambio la teoría sobre el currículum." (Estebaranz, 1996, p. 166).

A nuestro parecer la historia del curriculum en la postmodernidad ha evolucionado también en dos direcciones: una, aquella que responde esencialmente a la pregunta acerca de ¿qué conocimiento debe ser enseñado?; y otra, la que responde a las siguientes preguntas: ¿cómo estructurar el curriculum, equilibrarlo, organizarlo, secuencializarlo, establecer prioridades, evaluar consecuencias, guiar la interacción entre distintos constituyentes (personas, grupos, instituciones)?, además de ¿cómo orientar y supervisar la práctica de la enseñanza, y cómo dirigir la innovación y el cambio?.

Estas dos grandes tendencias tienen como implicaciones dos orientaciones epistemológicas fundamentales: la primera, orienta el hilo de sus investigaciones de la mano con la reflexión filosófica; y la segunda, orienta sus investigaciones hacia un elemento más pragmático como es la ingeniería del curriculum. Ambas posiciones resultaron ser equivocadas cuando radicalizaron sus posiciones; con la posición filosófica, se generó un proceso curricular para un sujeto en abstracto; con visión ingenieril, el curriculum dejó de ser un proceso artístico y creativo para sumirlo en un proceso instrumental y cosificado.

Pensamos que es necesario recuperar la dimensión filosófica del curriculum en el contexto de la crítica postmoderna, a fin de superar los criterios únicos de la Ilustración, el concepto de sujeto kantiano, los saberes objetivos absolutos y las verdades únicas. Lo cual permitiría analizar los quiebres que presenta el curriculum frente a las visiones postempiristas, el pensamiento complejo, y los enfoques que celebran la diversidad, la domesticación del azar y la tolerancia epistemológica; en este sentido, la profesora Monteiro (2005) de la Facultad de Educación, UNICAMP, Brasil, y Coordinadora e investigadora de GEPES-Grupo de Estudios e Investigación sobre Educación Superior, señala: "En esta perspectiva, el currículo no solamente posibilita ideas de forma lógica, estructurada e integrada como en el periodo regido por los parámetros de la modernidad, sino permite un sistema de ideas para ser explorado a partir de 
diferentes conexiones y de posibilidades aún no reveladas. El currículo es visto como proceso de conocimiento en una dimensión autoorganizadora y como posibilidad de explorar tanto lo conocido como lo desconocido. El currículo en esa dimensión permite al alumno y al profesor un repertorio creciente de posibilidades, de alternativas y una estimulación para intentar tantas combinaciones como sean posibles. En esa visión curricular no existe norma idealmente establecida o un canon que sirva como punto de referencia universal. Representa un sistema abierto, siempre en flujo y referente a un proceso transformativo y autogenerativo. Es un currículo que tiene cada vez más interrelaciones, que emerge en un proceso de redes." (Monteiro de Aguiar Pereira, 2005, p. 50).

Una tendencia desfilosofizada en la emergente teoría curricular sería repetir el error de la Modernidad que planteó enfoques únicos e hiperespecializados. Planteamos una relación transdisciplinaria en la que medie un diálogo entre la visión filosófica y la visión de ingeniería del curriculum, ya que, la discusión no es si ésta es más científica o si la primera es más cultura; el problema es plantear el riesgo que corren estos saberes al hacer una teoría del curriculum en forma unilateral.

\section{A manera de corolario}

Finalmente podemos establecer algunas conclusiones finales y una correlación con lo que significó los resultados del modelo curricular emergente. 1. El paradigma economicista fue clave para la consolidación de las teorías del curriculum que fortalecieran los modelos neoliberales; 2. Las teorías del curriculum, especialmente las alineadas con el Eficientismo social sirvieron de base para fomentar las tesis del curriculum y neoliberalismo; 3. A partir de la década del 80 y hasta 1998, la presencia de un modelo influenciado por el neoliberalismo impacto las teorías del curriculum, si bien ganando en términos de calidad, también generando efectos perversos por contra partida, como profundas desigualdades sociales traducidas en términos de exclusión y desigualdad de oportunidades para el ingreso y permanencia en el sistema escolar.

No obstante que el modelo político que se implantó en Venezuela desde 1998 se propuso superar la contracción de la matrícula escolar y superar el crecimiento negativo de la matrícula, no resultó sostenible. El llamado "milagro educativo" se hizo cenizas tan pronto comenzó la declinación del modelo bolivariano, que a nuestro modo de ver lo podemos determinar a partir de 2008; "El llamado milagro en educación que había significado el incremento de la matrícula escolar en la educación superior pronto se vio minimizada por las políticas que atacaron la productividad de conocimientos en las universidades oficiales, especialmente las tres universidades que se disputaban el $50 \%$ de la productividad nacional, como veremos a continuación. No cabe duda en las políticas educativas del Estado venezolano inicialmente hubo una propuesta innovadora, pero al mismo tiempo debemos alertar que fue una inclusión con crecimiento cuantitativo pero no cualitativo; fue una inclusión que tenía por característica una mayor desigualdad, pues no se puede incluir incorporando otra exclusión, como es la ausencia de calidad. Lo cual se fue corroborando con el tiempo. Ese perfil de crecimiento de manera sostenida no se pudo sostener. Hoy las universidades lucen desoladas y los alumnos no pueden asistir, los que quedan; porque la mayoría han migrado forzosamente, algunos en condición de refugiados luego de las más de 100 muertes violentas acaecidas en las 
manifestaciones del año 2017. Otros, son desplazados o migrantes forzados; fuentes autorizadas informan sobre el estado en que se encuentra la matrícula, en una de las dos primeras instituciones del ranking nacional, veamos: "en la Universidad de los Andes-Táchira, la deserción es un fenómeno que está afectando la matrícula, debido a que hay un abandono de las aulas (...) señaló que manejan un estimado aproximado de $45 \%$ de alumnos que abandonaron las aulas de la institución, lo que equivale a 3.500 estudiantes (...) la generación del futuro, que debe consolidarse académicamente, se está retirando para incorporarse a la economía informal o buscar alternativas laborales fuera del país. (...) Otra irregularidad que han observado en esta casa de estudios es que han aumentado las solicitudes de certificación de los programas y notas certificadas para ser utilizadas fuera del país. (...), lo más triste es que muchos profesionales, formados en calidad, se van del país a ejercer otras actividades. Entendemos la necesidad de cada estudiante, muchos se retiran para ayudar a sostener su hogar, porque el dinero no alcanza para la comida y mucho menos para pagar una residencia o el transporte." Por su parte la revista SIC, reconocida fuente de la Compañía de Jesús en Venezuela, nos aporta una serie de entrevistas sobre el estado actual de la matrícula en las universidades venezolanas; "En la UCV, la Federación de Centros Universitarios calcula la deserción estudiantil en $30 \%$ y el nivel de abandono de los profesores en $15 \%$.

En las universidades privadas se estima en $40 \%$ el retiro del estudiantado. Robinson Rivas, director de la Escuela de Computación de la UCV, lamentó que la universidad se esté quedando sin docentes con estudios de tercer nivel: doctorados y especialistas, cuya experiencia es vital para mantener la excelencia educativa (...), para este nuevo semestre en la Escuela de Computación sólo se inscribieron 700 alumnos de una plantilla original de 1.200 bachilleres; y con respecto a los docentes ya se nos han ido 20 (...) La Universidad Simón Bolívar (USB) no escapa a esta realidad. Muchos de sus profesores se fueron a Perú, Ecuador y Brasil, a través de programas de formación.

Pero, además del retiro de docentes que se van al exterior, esta casa de estudios debe enfrentar los problemas derivados de su ubicación en el Valle de Sartenejas, en Baruta, a donde cada vez es más difícil llegar por las fallas en el servicio de transporte (...) En las universidades privadas, el retiro de profesores y alumnos también mella la calidad educativa y la formación de nuevos profesionales." No sólo la crisis de la matrícula ha puesto a la universidad venezolana al borde del cierre, sino que los salarios de los profesores reducidos a un valor aproximado de unos 4 dólares mensuales; son los más irresponsables que gobierno alguno pudiera otorgar a sus profesores. Por si fuera poco, las restricciones que sufren los presupuestos de investigación, los proyectos de investigación y los incentivos para fortalecer los grupos de investigación, no sólo no alcanzan sino que resultan irrisorios frente a la escalada hiperinflacionaria." (Rojas \& Mora-García, 2019).

\section{Referencias}

Acevedo Tarazona, Á. (2017). Historia de un acontecimiento: Utopía y revolución en la universidad colombiana. Bucaramanga, Publicaciones UIS.

Albornoz, O. (1991). La educación y la crisis de la democracia social, del Populismo al Neoliberalismo. Discurso del 30 de septiembre de 1991. Ateneo de Caracas. 
Alvaray, G. et Al (1977). Caracterización de la realidad educativa nacional. Revista Papeles Universitarios. (4) 33-45

Arango, M. (1975). Lineamientos para el diseño de un Curriculum auténticamente latinoamericano. Caracas: O.E.A, M. E., USB.

Báez, de la Fe. (1991). El movimiento de las escuelas eficaces: implicaciones para la innovación educativa. Revista de Educación (294) (298-298)

Becerra, A. (2004). Thesaurus Curricular Universitario. Caracas:Instituto Pedagógico de Caracas.

Bloom, B. S. (1956). Taxonomy of educational objectives, handbook I: the cognitive domain. New York: David McKay Co.

Brinkerhoff, R. O., Brethower, D. M., Nowakowski, J., \& Hluchyj, T. (Eds.). (2012). Program evaluation: A practitioner's guide for trainers and educators (Vol. 2). Springer Science \& Business Media.

CAMPBELL D. T. y STANLEY, J. C. 1963. Experimental and quasi-experimental designs for research on teaching, en N. L. Gage (comp.), Handbook of research on teaching, Chicago, Rand McNally.

Cárdenas, A. (1998). Educación para todos (de una educación de masas a una educación para todos) Caracas: IPASME.

Carvajal, Gabriel A. (1983). Educación Básica. Proyecto Educativo (Guía ilustrada). ULA-NURR, Mimeo. Trujillo.

Castro, M. (1984). Evaluación Curricular aproximado a un Modelo. Caracas:UNA

Coleman, J. S. (1968). Equality of educational opportunity. Integrated Education, 6(5), 19-28.

Cook, D. L. (1971). Program evaluation and review technique: Applications in education (No. 17). US Government Printing Office.

Corporation.Joint Committee on Standards for Educational Evaluation. (1981). Standards for evaluations of educational programs, projects, and materials, Nueva York, Mc Graw-Hill.

Cronbach, L. J. (1963). Course improvement through evaluation, Teachers College Record, 64, págs. 672-683.

Cronbach, L. J., Ambron, S. R., Dornbusch, S. M., Hess, R. D., Hornik, R. C., Phillips, D. C., ... \& Weiner, S. S. (1980). Toward reform of program evaluation (p. 3). San Francisco: Jossey-Bass.

Díaz, Á. \& García, J (2014). (Editores) La evolución del campo del currículo en América Latina. Bs. As.: Miño\&Dávila.

Eisner, E. W. (1975). The perceptive eye: Toward the reformation of educational evaluation.

Giroux, H. (1997). Cruzando límites, trabajadores culturales y políticas educativas. México: Paidós.

Glaser, R. (1963). Instructional technology and the measurement of learning outcomes: Sorne questions, American Psychologist, 18 (1963), págs. 519-521.

Glass, G. (1976). Primary secondary and meta analysis of research, Educational Researcher, 5(10), págs. 3-8.

Goodson, I. (2000). El Cambio en el curriculum. Barcelona: Editorial Octaedro.

Granier, M. (1985). La Generación de Relevo Vs. el Estado Omnipotente. Caracas: Seleven. 
Guba, E. G. (1996). A Study of Title III activities: Report on evaluation» (National institute for the Study of Educational Change, Universidad de Indiana, octubre de 1966) (ciclostilado).

Guba, E. G. y LINCOLN, Y. S. (1981). Effective evaluation, San Francisco, Washington, Londres, Jossey-Bass.

Guédez, V. (2005). "La diversidad y la inclusión: Implicaciones para la cultura y la educación en Arellano, A. (Coord). La educación en tiempos débiles e inciertos. 205-234). Barcelona: Anthropos.

Hammond, R. L. (1967). «Evaluation at the local level». Conferencia para el Miller Committee for the National Study of ESEA Title III.

Hernández, H. (1971). Nuevos aportes a la reforma educativa. Caracas: Ministerio de Educación. Dirección de Planeamiento.

Herrera, H. (2015). Educabilidad y justicia social en tiempos de neoliberalismo, XII Congreso Nacional de Educaçao, Brasil. (Consulta 20 octubre 2018) http://educere.bruc.com.br/arquivo/pdf2015/21563_10118.pdf

Herrera, M. \& López, M. (1996). La eficacia escolar. Caracas: CICE/CINTERPLAN Hurtado, I. (1997). Universidad y Proceso Histórico. Valencia: Oficina del CronistaUniversidad de Carabobo.

Johnson, R. (1980). Directory of evaluators and evaluation agencies, Nueva York, EXXON.

Kaplan, A. (1964). The conduct of inquiry, San Francisco, Chandler.

Kellaghan, T. (1982). Los sistemas escolares como objeto de evaluación. En Daniel STUFFLEBEAM; Thomas KELLAGHAN; y Benjamín ÁLVAREZ (comp.), La Evaluación Educativa, Bogotá, Pontificia Universidad Javeriana.

Kliebard, H. (1986) The struggle for the American Curriculum (1893-1953). London. Routledge \& Kegan Paul.

León, J. (1992). El Neoliberalismo en la Educación Venezolana. Revista Fermentum (5) 33-38.

López, M. (2003) Los estudios sobre escuelas eficaces en Venezuela en Murillo, F. et Al (2003). La investigación sobre eficacia escolar en Iberoamérica. Caracas:Ministerio de Educación Cultura y Deportes.

Marcelo, C. (1995) la Formación del profesorado para el cambio educativo. Barcelona: EUB.

Mclaren, P. (1989). La vida en las escuelas. México: Siglo XXI.

Mogollón, A. (2004). Modelo para la supervisión educativa en Venezuela. Revista Ciencias de la Educación. (23) 30-45.

Montilla, J. (2/12/2004). "Fuga de Talentos del $3^{\circ}$ mundo hacia EEUU," Diario Últimas Noticias, 17.

Mora, J. (1994). Estrategias para una Gerencia Educativa Postmoderna. Tesis Mimeografiada para optar a la Maestría en Gerencia Educativa, en la Universidad Nacional Experimental del Táchira. San Cristóbal. Venezuela.

Mora, J. (2000). ¿Existe un curriculum postmoderno?. (de las teorías curriculares de la Modernidad al currículum postmoderno). Rev. UNIVERSITAS TARRACONENSIS, Rev. Ciencies de L’Educació. Año XXIV, III época. TarragonaEspaña.

Mora, J. (2004). El curriculum como historia social (Aproximación a la historia del curriculum en Venezuela). Revista de Teoría y Didáctica de las Ciencias Sociales, ISSN-e 1316-9505, №. 9, 2004, págs. 49-74. 
Mora, J. (2013). Historia del curriculum en Venezuela: fuentes y comunidades académicas (1936-1998) Vol. 16 Núm. 16 (2013): Historia de la Educación Colombiana. https://revistas.udenar.edu.co/index.php/rhec/article/view/1745

Mora. J. (2014). El curriculum en Venezuela: del eficientismo social de Raph Tyler a la postmodernidad. (1970-1997), en Ángel Díaz-Barriga \& José María García Garduño (Coords) Desarrollo del currículo en América Latina. Miño\&Dávila, Argentina, 2014.

Navarro, J. (1991). El impacto del gasto público en educación en Venezuela., AA.VV (1991) Gestión Fiscal y distribución del Ingreso en Venezuela. Caracas: IESA.

Peters, T. \& Austin, N. (1994). Pasión por la excelencia. Barcelona:Folio

Peters, T. (1994). En búsqueda de la excelencia. Barcelona:Folio

Ramos, F. \& Castro, J. (2014). La Alianza para el Progreso en Chile y Venezuela, 1961-1963. Revista Tiempo y Espacio (62). (90-98).

Reimers, F. (1992). Educación en Venezuela y los desafíos del siglo XXI. Revista Universitas 2000, (16) (16-25).

Requena, J. (2011). Ciencia y poder, eco de sus conflictos. San Cristóbal: Fondo Editorial Simón Rodríguez.

Roche, M. (1987). Hacia dónde marcha la ciencia en Venezuela. Caracas: Monte Avila.

Rodríguez, N. (1989). La Educación Básica en Venezuela. Proyectos, realidades y perspectivas. Caracas: Biblioteca de la Academia Nacional de la Historia.

Rojas, R. (2009). Balance teórico-metodológico de las líneas de investigación: historia social e institucional de la educación en Venezuela y pedagogía, currículo y formación docente en Venezuela." Revista de Ciencias Sociales de la región centroccidental. Barquisimeto: Publicación del Centro de Investigaciones Históricas de América Latina y el Caribe (CIHALC) y Fundación Buria. (13-14). (125.ss).

Rojas, R., \& Mora García, J. (2019). Políticas educativas en Venezuela (20002016): Una mirada crítica. Revista Historia De La Educación Latinoamericana, 21(32), 155-192. https://doi.org/10.19053/01227238.9483

Ruíz, H. (1997). Tras el fuego de Prometeo, becas en el exterior y modernización en Venezuela (1990-1996). Mérida: CDCHT-ULA, FUNDACITE.

Salcedo, H. (1980) Perspectivas actuales en evaluación educacional. Algunas implicaciones. Curriculum. Revista especializada para América Latina y el Caribe. (9) (84-98).

Sánchez A. (1982) Curriculum sistémico. Caracas: OEA- USB, M.E.

Sánchez, J. (2014) Los debates en el currículo universitario. Realidades y desafíos. Revista Saber, Universidad de Oriente. (26) (68-86)

Scriven, M. S, (1975). Evaluation bias and its control. Occasional Paper Series, n. 4, Universidad de Western Michigan. Centro de Evaluación.

Scriven, M. S. (1967). The methodology of evaluation En Perspectives of curriculum evaluation (AERA Monograph Series on Curriculum Evaluation n. 1), Chicago, Rand McNally.

Scriven, M. S. (1974). Prose and cons about goal-free evaluation, Evaluation Comment, 3, páginas 1-4.

Smith, E. R. Y Tyler, R, W. (1942). Appraising and recording student progress, Nueva York, Harper. 
Smith, N. L. (1975). Program evaluation, Particularly responsive evaluation. Occasional Paper Series n. 5, Universidad de Western Michigan, Centro de Evaluación.

Smith, N. L. (1978). The case-study method in social inquiry, Educational Researcher 7, páginas 5-8.

Smith, N. L. (1981). Setting standards for educational evaluators. Evaluation News n. 2, 2 (1981), págs. 148-152.

Smith, N. L. (1981a). Metaphors for evaluation: Sources of new methods, Beverly Hills, Sage.

Smith, N. L. (1981b). New techniques for evaluation, Beverly Hills, Sage.

Sosa, A. (1998) Palabras de Arturo Sosa en Sosa, P.; Carmargo, L.; Carmargo, E. (Comp) Asamblea Nacional de Educación. Discurso y ponencia. Tomos I y II. Caracas:Consejo Nacional de Educación

Stake, R. E. (1967). The countenance of educational evaluation, Teachers Collage Record, 68, págs. 523-540.

Stufflebeam, D. L. (1967). The use and abuse of evaluation in Title III, Theory Into Practice, 6 (1967), págs. 126-133.

Stufflebeam, D. L. (1978). Metaevaluation: An overview, Evaluation and the Health Professions, 1 (2), págs. 146-163.

Stufflebeam, D. L., y otros. (1971). Educational evaluation and decision making, Itasca, III., Peacock.

Suárez, T. (1980). Needs assessments for technical assistance: A conceptual overview and comparison of three strategies. Tesis doctoral inédita. Universidad de Western Michigan.

Tedesco, J. (1986) Paradigmas de la Educación en América Latina, Rev Colombiana de Educación, (18) 131-138.

Toro, A. (2009) La Escuela de Educación de la Universidad de Carabobo: Historia, Pedagogía y Curriculum (1960-2000). Caracas: Consejo Nacional de universidades.

Tyler, R. W. (1967). Changing concepts of educational evaluation. En R. E. Stake (comp.), Perspectives of curriculum evaluation (vol. 1), Nueva York, Rand McNally. UNESCO. (1974) Seminario sobre Técnicas de Evaluación del Curriculum. Informe final de la Comisión. № 2, octubre, Caracas.

Villamizar, G. (1995) Maestros y alumnos: dos rescates necesarios Ponencia en Pedagogía 95. La Habana. Cuba. 